\title{
Self-reported morbidity data as an indicator regional resource requirement
}

\author{
RICHARD DAJDA
}

From the Medical Sociology Research Centre, University College of Swansea

SUMmaRY In this paper five variables are taken from the General Household Survey and the statistical technique of multidimensional scaling is used to estimate the relationships between the $\vec{\nabla}$ standard economic regions of England and Wales in terms of their self-reported morbidity. An $\cong$ estimate is then made of the proportion of resources that must be allocated to each region in order ${ }^{\infty}$ to eliminate the differences found. The five variables measuring longstanding illness; limiting.. longstanding illness; restricted activity; certificated absence; and general practitioner consultation $\overrightarrow{\vec{\omega}}$ were standardised, and input to a multidimensional scaling programme. This showed that the $\stackrel{\omega}{\omega}$ English regions were very similar to each other, although a morbidity continuum could be identified which corresponded to the North-South variation in socioeconomic conditions found in $\stackrel{\vec{\omega}}{?}$ England. Wales, however, shows considerable difference from the English regions, a difference $\omega_{j}^{\omega}$ which cannot be explained purely in terms of the socioeconomic conditions in the region. For thäs reason a far more detailed investigation is proposed.

In the report of the Resource Allocation Working Party (Department of Health and Social Security, 1976) morbidity data were not thought suitable for inclusion in the resource allocation formula. Instead, mortality data in the form of standardised mortality ratios were used as a proxy measure of regional morbidity variation. This decision has been widely criticized (Barr and Logan, 1977; Forster, 1977; 1978; Snaith, 1978).

This paper shows that there exists a statistical technique that can be used to examine the interrelationships between regions in terms of their self-reported morbidity and can provide an estimate of the proportion of resources that should be allocated to each area in order to reduce the self-reported morbidity to that of the best region.

SELF-REPORTED MORBIDITY DATA

The data used in this paper are taken from the General Household Survey (GHS), a continuous stratified national survey conducted by the Social Survey Division of the Office of Population Censuses and Surveys (OPCS, 1973). Approximately 12000 households are sampled every year in Great Britain, yielding roughly 30000 individuals. The sample is stratified by the standard economic regions and is representative at this level but no lower.

The GHS covers a variety of topics of interest to Government departments, who liaise with the Office of Population Censuses and Surveys in the formulation of questions for the interview schedulew.

The GHS contains both personal and household $\vec{\theta}$ information, and a large part of the personat $c$ questionnaire consists of health questions. These cover a wide range, from self-reported illness, use of GP services, and self-medication to use of hospitals' inpatient and outpatient facilities, but this paper concentrates on a few of the measures of $\frac{\alpha}{\Phi}$

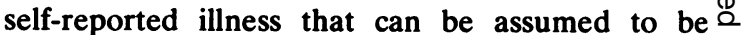
independent of the level of service provided. Hence $\overrightarrow{\overrightarrow{0}}$ variables such as use of hospital facilities have been 3 ignored as being directly dependent upon the regional availability of such provisions.

It is realised that self-reported morbidity will not

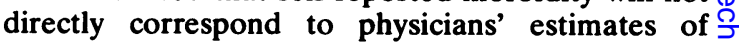
demand for services, and that much self-reported $\overline{0}$ morbidity will be of a trivial nature. However, it is believed that the variables used here are of a $\delta$ sufficiently non-trivial nature to warrant a meaningful analysis.

Table 1 gives the wordings of the questions in the GHS from which the variables in this study were derived. Because of the relatively low number of $\mathrm{N}$ persons answering the health questions, especially $ᄋ$ when broken down by region, data for the years 1973 N to 1976 were aggregated.

The GHS data were standardised over regions and $O$ are given in Table 2 , which shows that there is a 
general upward trend from East Anglia and the southern English regions up to the northern regions and Wales, with the latter considerably higher than the rest on all measures.

Table 1 Wording of GHS questions used to derive study variables

\begin{tabular}{ll}
\hline Mnemonic & Question \\
\hline LONGSTANDING & $\begin{array}{l}\text { Do you have any long-standing illness, } \\
\text { disability or infirmity? }\end{array}$ \\
LIMITING & Does (-) limit your activities in any way? \\
RESTRICTING & $\begin{array}{l}\text { During the two weeks ending last Sunday, did you } \\
\text { have to cut down on any of the things you usually } \\
\text { do because of illness or injury? }\end{array}$ \\
CERTABS & $\begin{array}{l}\text { (If yes to RESTRICTING and yes to Did (-) } \\
\text { (other than housework) or school during the two } \\
\text { weeks which ended last Sunday? then) } \\
\text { Did you have a medical certificate to cover any of } \\
\text { these days? }\end{array}$ \\
CONSULT & $\begin{array}{l}\text { During the two weeks ending last Sunday, } \\
\text { apart from visits to a hospital, did you talk to } \\
\text { a doctor for any reason at all? }\end{array}$ \\
\hline
\end{tabular}

\section{A REGIONAL MEASURE OF MORBIDITY}

The broad problem is to determine a single measure which reflects each region's overall score on all of the measures given. The obvious statistic to use is the mean, but this will mask some of the individual differences and similarities between the regions. For this reason it was decided to use the statistical technique known as multidimensional scaling.

\section{MULTIDIMENSIONAL SCALING}

Multidimensional scaling (MDS) can be viewed as an attempt to provide a graphical representation of the relationships between the objects of interest, in this case economic regions. Given a set of objects and a measure of their dissimilarity (or similarity), MDS attempts to plot a number of points so that the distances between the points correspond to the differences between the objects.

A matrix of dissimilarities was computed from the data in Table 2. For each pair of regions the difference in value for each variable was taken. These differences were summed for all five variables, giving a total which reflects the dissimilarity between the two areas.

For example, the dissimilarity between the East Midlands and the North-west is given by:

$$
\begin{aligned}
& (0.38-0.45)+(0.01-0.29)+(-0.14-0.50)+(-0.63-0.38) \\
& +(-0.50-0.11)=-2.61
\end{aligned}
$$

The absolute values of any negative scores were taken, giving a dissimilarity between the East Midlands and the North-west of $2 \cdot 61$.

The matrix was input to a multidimensional scaling computer programme originated by E. E. Roskam of Nijmegen University and J. C. Lingoes of Michigan University. The actual programme used was the one developed by the Program Library Unit of Edinburgh University (PLU, 1977).

\section{THE MDS RESULTS}

The output from the MDS programme has been plotted in the Figure. The axes plotted are in essence arbitrary, having been plotted to give a frame of reference for the points. Similarly, the actual distances between the points are not meaningful. What is all-important is the ratios of the distances between the points. That is, the nearer together are two points the more alike are the two objects represented by the points. Thus the South-west and South-east regions are so similar as to be almost indistinguishable, like the West Midlands and Yorkshire and Humberside. However Wales is extremely dissimilar from all the other regions, and, to a lesser extent, so is East Anglia.

The Figure is a graphical representation of the underlying relationships between the regions as expressed in the standardised morbidity variables presented in Table 2 . The nearer are two regions, the more similar they are in terms of the self-reported morbidity of these regions.

Four clusters can be identified, the South-west and the South-east forming cluster 1, Wales and East Anglia forming single-point clusters 2 and 3, and the remaining regions forming cluster 4. East Anglia is slightly separated because the morbidity it shows is very much lower than the others; conversely, Wales is

\begin{tabular}{|c|c|c|c|c|c|c|c|c|c|}
\hline & $\begin{array}{l}\text { East } \\
\text { Anglia }\end{array}$ & $\begin{array}{l}\text { South- } \\
\text { west }\end{array}$ & $\begin{array}{l}\text { South- } \\
\text { east }\end{array}$ & $\begin{array}{l}\text { East } \\
\text { Midlands }\end{array}$ & $\begin{array}{l}\text { West } \\
\text { Midlands }\end{array}$ & $\begin{array}{l}\text { Yorkshire and } \\
\text { Humberside }\end{array}$ & North & $\begin{array}{l}\text { North- } \\
\text { west }\end{array}$ & Wales \\
\hline $\begin{array}{l}\text { LONGSTANDING } \\
\text { LIMITING } \\
\text { RESTRICTING } \\
\text { CERTABS } \\
\text { CONSULT }\end{array}$ & $\begin{array}{l}-1 \cdot 35 \\
-1 \cdot 19 \\
-1.42 \\
-1.68 \\
-1.25\end{array}$ & $\begin{array}{l}-1 \cdot 14 \\
-0.28 \\
-0.87 \\
-0.70 \\
-0.22\end{array}$ & $\begin{array}{r}-0.92 \\
-0.99 \\
0.22 \\
-0.32 \\
-0.72\end{array}$ & $\begin{array}{r}0.38 \\
0.01 \\
-0.14 \\
-0.63 \\
-0.50\end{array}$ & $\begin{array}{r}-0.34 \\
-0.54 \\
0.60 \\
0.25 \\
0.34\end{array}$ & $\begin{array}{r}0.13 \\
-0.32 \\
-1 \cdot 12 \\
0.72 \\
0.26\end{array}$ & $\begin{array}{r}0.84 \\
0.66 \\
0.18 \\
-0.13 \\
-0.51\end{array}$ & $\begin{array}{l}0.45 \\
0.29 \\
0.50 \\
0.38 \\
0.11\end{array}$ & $\begin{array}{l}1 \cdot 96 \\
2 \cdot 37 \\
2 \cdot 06 \\
2 \cdot 11 \\
2 \cdot 48\end{array}$ \\
\hline MEAN & $-1 \cdot 38$ & -0.64 & -0.55 & -0.12 & 0.06 & 0.07 & 0.21 & 0.35 & $2 \cdot 20$ \\
\hline
\end{tabular}

Table 2 Standardised measures of morbidity for the standard economic regions of England and Wales 
separated because it shows very much higher morbidity than the remaining regions.

By and large the regions are most similar to their geographical neighbours: the South-west is similar to the South-east and the East Midlands is similar to Yorkshire and Humberside. This is to be expected given the arbitrary nature of geographical boundaries.

The Figure shows that the regions lie roughly on a straight line, apart from Wales. The ordering of the regions upon this line is very similar to the ordering of the regions in terms of their mean standardised score given as the last row of Table 2. This would seem to indicate that the eight regions of England are on a continuum of morbidity, from the lowest, East Anglia, to the highest, the North-west. This continuum is very similar to the North-South differences in socioeconomic conditions shown by the standard regions. Wales however, does not lie on this continuum but is radically different from the English regions. Part of this difference stems from the fact that while the English regions (except for East Anglia, which is low on all variables), tend to be high on some of the five initial variables and low on others, Wales is consistently high on all the variables.

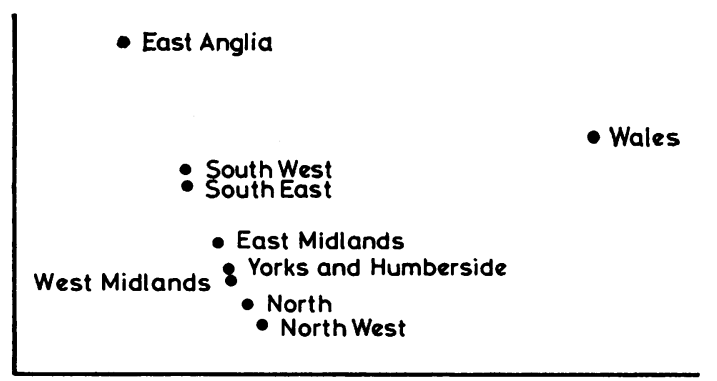

Figure Two-dimensional solution from MDS programme.

\section{Discussion}

The multidimensional scaling programme has provided a representation of the relationship between regions in terms of their self-reported morbidity, emphasising the radical difference between Wales and the English regions, in a manner that is immediately recognisable.

The Figure can also be used to provide the index this paper has set out to discover, a single measure for each region which reflects the regions' overall position on all of the variables, with East Anglia at the 'good' end of the scale and Wales at the 'bad' end. This measure is the distance on the plot of each region from the 'best' region, East Anglia. This figure can be used to allocate revenue to regions in terms of their morbidity. If the aim is to bring all regions up to the level of the best region, East Anglia, then (assuming a direct relationship between allocation of funds and reduction of morbidity) any funds specifically allotted for the reduction of regional differences in morbidity should be distributed according to the formula:

Distance from best region

Sum of distances from best region

This gives a proportion because, as was stated earlier, the MDS programme provides the ratios between regions rather than any absolute measure of morbidity for any given region.

Table 3 gives the distances from the best region and the percentage of any available funds that would have to be distributed to each region in order to bring it up to the level of the best region, East Anglia. What is immediately noticeable in Table 3 is the considerable amount of funds that would have to be allocated to Wales. It is only when the high morbidity of Wales is seen in these terms that the difference between Wales and England is fully appreciated.

Table 3 Regional allocation of funds in terms of morbidit

\begin{tabular}{llll}
\hline Region & $\begin{array}{l}\text { Distance from } \\
\text { best region }\end{array}$ & \% of funds \\
\hline East Anglia & 0.0 & 0.0 & 6.8 \\
South-west & 0.97 & 7.4 & 10.8 \\
South-east & 1.06 & 11.7 & 12.7 \\
East Midlands & 1.55 & 14.2 & \\
Yorkshire and Humberside & 1.67 & 15.4 \\
West Midlands & 1.82 & 21.0 \\
North & 2.03 & 2.21 & \\
North-west & 3.00 & \\
Wales & &
\end{tabular}

There are, of course, several drawbacks to the use of the above analysis in the process of resource allocation. The General Household Survey is stratified so that it is representative for the standard economic regions used in this analysis. The data cannot be used for the Regional Hospital Authority Areas that are used in NHS resource allocation.

Furthermore, the data are purely a subjective measure of perceived need. However, the GHS morbidity data are the best morbidity data available (Dowie, 1978). The only other source of detailed regional morbidity data is the National Morbidity Survey (Office of Population Censuses and Surveys, 1974) and the representativeness of those data is suspect (Forster, 1978; Palmer, 1978).

Until more research can be conducted, the GHS will be the definitive work specifying regional variations in morbidity, but it is widely agreed that further household surveys, with a specific interest in health, must be undertaken, (Barr and Logan, 1977; Bowie, 1978; Forster, 1978). For Wales to show such 
a great difference from the English regions, there must be factors operating other than the usually recognised relationship between the socioeconomic standing of a region and its level of health. From the socioeconomic conditions in Wales one would expect high morbidity, but not as high as discovered here. It is likely that the most powerful factors operating are cultural (Dowie, 1978), and a health-based household survey will be the best means to identify these.

\section{Conclusions}

Five measures of self-reported morbidity have been used to examine the interrelationships between the standard economic regions of England and Wales. Using the statistical technique of multidimensional scaling, these relationships have been graphically portrayed. In general the regions of England are similar, but show a gradation in terms of morbidity along the North-South axis of England which corresponds to the socioeconomic differences. However, Wales exhibits extremely high self-reported morbidity, in excess of that which would be expected from simple socioeconomic conditions, and it is hypothesised that this excess can be explained in cultural terms.

National morbidity data are still available only in a very limited form; hence a regional morbidity survey is becoming a prerequisite for any further explanation of area differences in health. It is appropriate to conclude with a quotation from a paper by Barr and Logan (1977): 'A sample household survey is the vital linchpin in specifying what the public requires from the whole gamut of social-welfare planning, including health services, and particularly the extent of unmet need and inadequacy of services within the community. It is a sobering reflection that the methodology to pursue such studies has existed for thirty years, yet these critical questions remain unanswered'.

I thank the Social Survey Division of the Office of Population Censuses and Surveys and in particular Catherine Ellis for providing aggregated General Household Survey data. The opinions expressed here are entirely those of the author and not necessarily those of the OPCS.

Reprints from Richard Dajda, Medical Sociology Research Centre, University College of Swansea, Park Buildings, Park Street, Swansea SA1 3DJ.

\section{References}

Barr, A., and Logan, R. G. L. (1977). Policy alternatives for resource allocation. Lancet, 1, 994-997.

Department of Health and Social Security (1976). Sharing Resources for Health in England. Report of the Resource Allocation Working Party. HMSO: London.

Dowie, R. (1978). Demographic and socioeconomic indices and sickness absence statistics: their relevance as morbidity indicators. In Morbidity and its Relationship to Resource Allocation. Edited by Sir John Brotherston. HMSO: London.

Forster, D. P. (1977). Mortality, morbidity and resource allocation. Lancet, 1, 997-998.

Forster, D. P. (1978). Mortality as an indicator of morbidity in resource allocation. In Morbidity and its Relationship to Resource Allocation. Edited by Sir John Brotherston. HMSO: London.

Office of Population Censuses and Surveys (1973). The General Household Survey. Introductory Report. HMSO: London.

Office of Population Censuses and Surveys (1974). Morbidity Statistics from General Practice. Second Study 1970-71. Studies on Medical and Population Subjects, No. 26. HMSO: London.

Palmer, S. R. (1978). The use of mortality data in resource allocation. In Morbidity and its Relationship to Resource Allocation. Edited by Sir John Brotherston. HMSO: London.

Program Library Unit, University of Edinburgh (1977). The MDS (X) Series of Multi-Dimensional Scaling Programs: Minissa Program. Inter-University/Research Councils Series, Report No. 32.

Snaith, A. H. (1978). Subregional resource allocations in the National Health Service. Journal of Epidemiology and Community Health, 32, 16-21. 